\title{
INTRODUCTION OF LEPTODACTYLUS FALLAX IN PUERTO RICO
}

\author{
T. B. McClemLand, Director,
}

Porto Rico Agricultural Experiment Station, Mayagüez, P. R.

The Federal Experiment Station of Mayagüez has made two importations of Leptodactylus fallax, the "mountain chicken" or large edible frog of Dominica, with the object of establishing this species in Puerto Rico.

The first lot of 12 frogs was received from Dominica July 1929. They were released on the shore of the Cartagena Lagoon, a location which had proved highly favorable for the development of the toad, Bufo marinus, introduced by the station in 1920 from Barbados. Whether or not the frogs persisted is not known. Later attempts to definitely locate them failed.

In June of the present year a second and larger lot was imported from the same source. Ninety individuals were received alive. Fifty were released on the bank of the reservoir located on the station farm just north of Mayagüez, and forty were released on the river bank near Las Vegas.

Their loud call from one point or another on the station grounds was frequently heard at night thereafter, and in November a young frog of this species was found.

This species is shown in colors in the National Geographic Magazine, May, 1932 and under the plate is the legend: An Edible Species In Some Danger of Extermination. Let us hope that its introduction into Puerto Rico may not reduce the danger of extermination, but that it may also supply the Island with an epicurean dish not previously procurable. 